\title{
LONGITUDINAL OSTEOTOMY OF THE TIBIA
}

\author{
(The "Reed" Osteotomy) \\ O. R. Nicholson, Auckland, New Zealand \\ From the Institute of Orthopaedics, Royal National Orthopaedic Hospital, London
}

Many methods of osteotomy have been described for the correction of torsional deformities of the tibia. The method of longitudinal osteotomy described by Haas (1929) is not widely known and has not been subsequently reviewed. Haas described three cases in which the operation had been performed; two operations were on the tibia and one on the femur. Its use for the correction of femoral torsion was described in the first edition of Campbell's Operative Orthopedics (1939), but the description was omitted from subsequent editions. The method was introduced to the Royal National Orthopaedic Hospital in 1930 by $\mathrm{Mr}$ H. J. Seddon, who had seen the operation performed in the United States of America. It has since been used with satisfactory results as the routine method of correcting tibial torsion and minor degrees of associated angular deformity.

The method, to quote Haas, "depends on the principle that if a series of longitudinal osteotomies are made about the circumference of a bone, they will so weaken the structure that it will yield in any direction to bending or twisting forces and still maintain the continuity of the bone." In the original description multiple longitudinal cuts (five or six) were made with an osteotome through both cortices of the upper tibia to allow correction of both lateral deviation and rotation of the tibia.

\section{TECHNIQUE OF OPERATION}

The proximal half of the tibial shaft is exposed through an incision over the subcutaneous surface and the periosteum is reflected over a length of about four inches.

Longitudinal saw cuts about an eighth of an inch apart are made with a motor saw, care being taken that the blade is kept cool with saline. In this way approximately two-thirds of the circumference of the tibia is converted into strips like reeds. The residual bridge posteriorly is then divided transversely at about its middle with an osteotome or with a Gigli saw (Fig. 1).

When a twisting force is applied the individual " reeds" rotate and the deformity is corrected. On occasions, however, particularly in older patients, there may be some resistance to rotation and this may be overcome by dividing alternate " reeds" transversely at their proximal and distal ends, thus leaving interdigitating strips (Fig. 2). Fracture of some of the " reeds" may occur during the manipulation without impairing stability. It is seldom necessary to divide the fibula. The position after manipulation in a case in which division of the " reeds" was not necessary is shown in a radiograph (Fig. 3).

The wound is closed and the limb is immobilised in an above-knee plaster in a slightly over-corrected position and with the knee flexed at least 30 degrees to maintain position.

The plaster is changed after two weeks, when the position may be adjusted. If there is an associated valgus or varus deformity the second plaster must be applied with the knee extended. Immobilisation is continued until the bone has united.

\section{RESULTS}

Records are available of thirty-eight operations carried out on thirty patients. The conditions for which these operations were performed and the results are summarised in Table I. In one patient the method was used as part of the procedure described by van Nes 


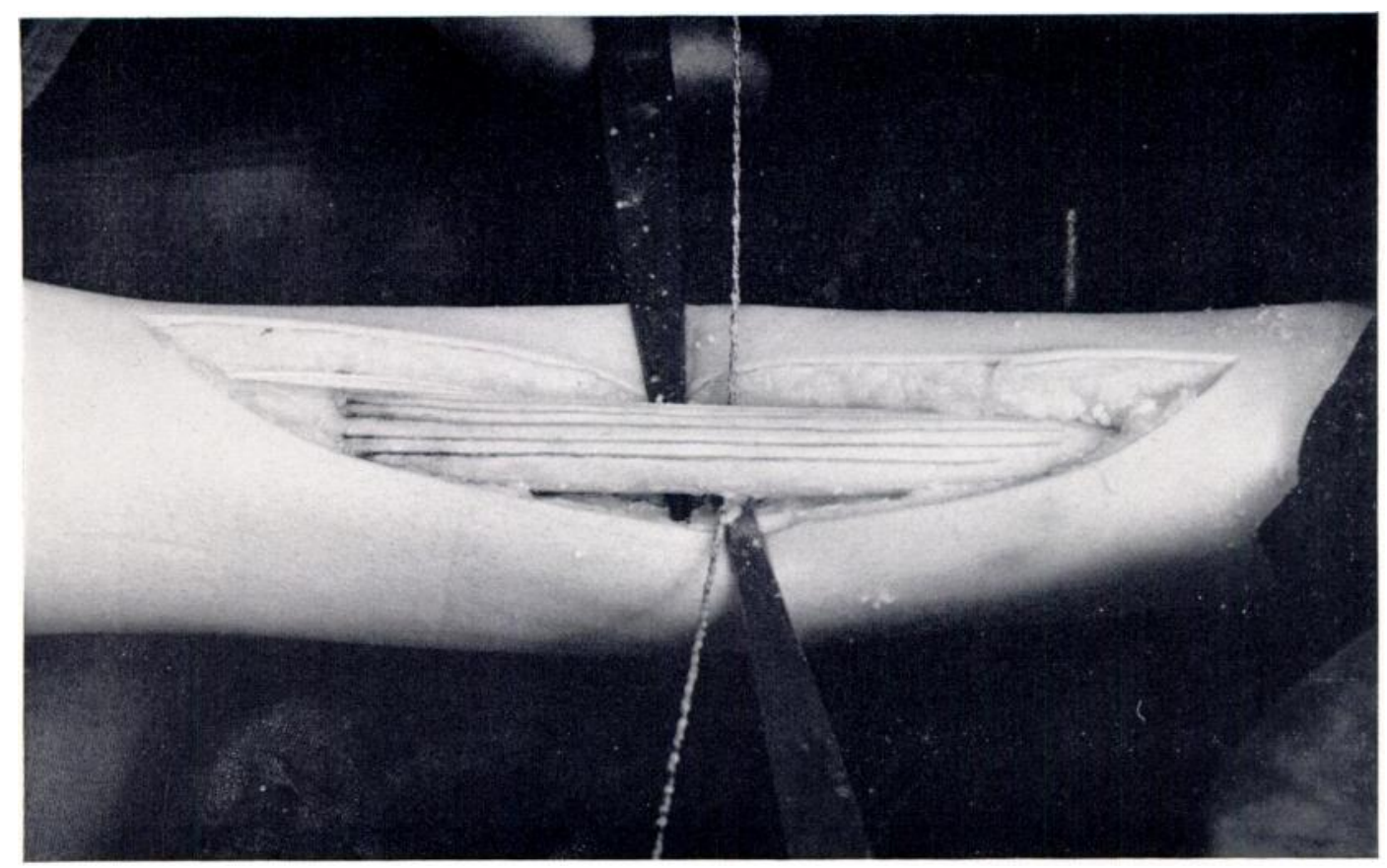

FIG. 1

Multiple longitudinal saw cuts have been made and the posterior cortex is being divided transversely with a Gigli saw. It is usually possible then to correct the deformity by manipulation.

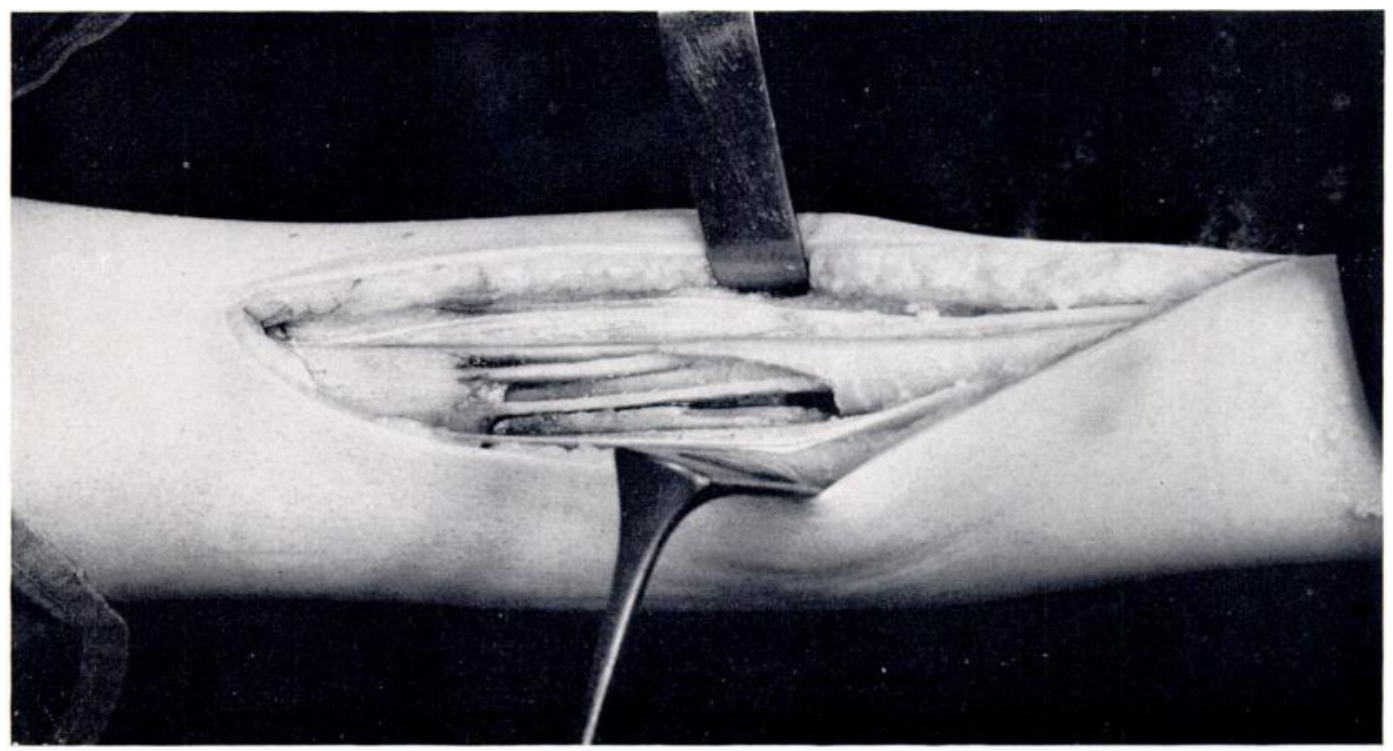

FIG. 2

Final position after division of alternate reeds at their proximal and distal ends. The rotational correction obtained in this case was about 60 degrees. 
(1950) and 100 degrees of rotation were obtained. A partial relapse occurred in this case and the operation was repeated five years later.

Union was generally complete in eight to twelve weeks, when the clinical correction was always satisfactory.

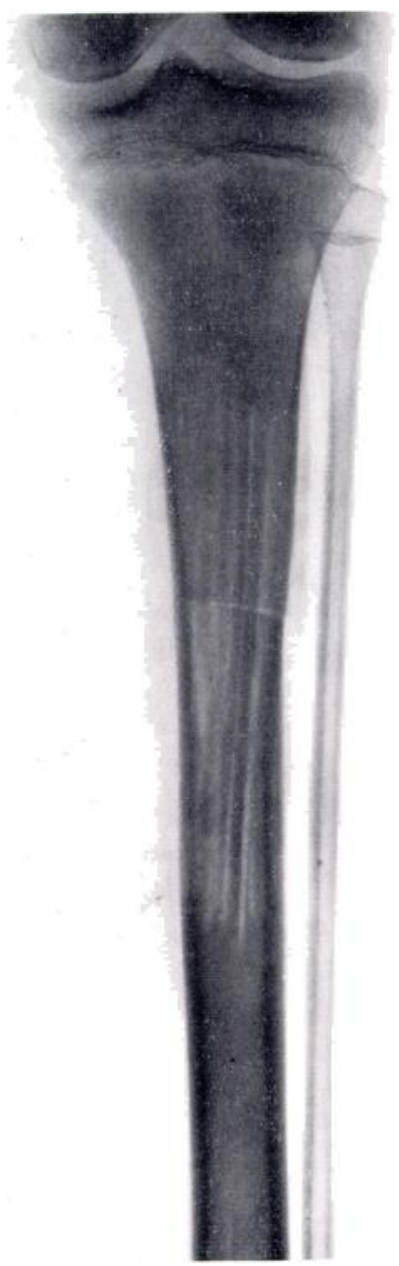

FiG. 3

Radiograph showing position at the end of the operation. In this case division of the " reeds" was not necessary.

\section{COMPLICATIONS}

Vascular and nervous complications have not occurred in this series.

Non-union occurred in three patients, all young adults (Table I). The only cause that can be suggested for the failures is that in adults the extensive periosteal stripping seriously interferes with the blood supply to the bone. It therefore seems preferable to reserve this method for patients under the age of twenty years.

Fracture occurred in one patient six months after operation and three months after removal of the plaster, but the fracture was undisplaced and united after a further period of immobilisation. 
TABLE I

SumMary OF THIRTY-EIGHT OPERATIONS

\begin{tabular}{|c|c|c|c|c|}
\hline Diagnosis & $\begin{array}{c}\text { Number of } \\
\text { Patients }\end{array}$ & $\begin{array}{l}\text { Number of } \\
\text { Operations }\end{array}$ & $\begin{array}{l}\text { Age range } \\
\text { in years }\end{array}$ & Complications \\
\hline Poliomyelitis . . . & 11 & 11 & $6-25$ & $\begin{array}{l}\text { Non-union in one case (patient } \\
\text { aged } 25 \text { years). Treated by bone } \\
\text { grafting }\end{array}$ \\
\hline Congenital talipes equinovarus . & 8 & 13 & $2-11$ & \\
\hline Congenital tibial torsion . & 2 & 2 & $5-22$ & $\begin{array}{l}\text { Non-union in one case (patient } \\
\text { aged } 22 \text { years) }\end{array}$ \\
\hline $\begin{array}{l}\text { Tuberculosis of hip } \\
\text { Osteomyelitis of femur } \\
\text { (deformity developed during pro- } \\
\text { longed immobilisation on frame) }\end{array}$ & 3 & 3 & $6-25$ & $\begin{array}{l}\text { Non-union in one case (patient } \\
\text { aged } 25 \text { years). Treated by bone } \\
\text { grafting }\end{array}$ \\
\hline Still's disease . & 2 & 2 & $9-16$ & \\
\hline Rickets . & 2 & 3 & $6-7$ & \\
\hline $\begin{array}{l}\text { Congenital absence of proximal } \\
\text { part of femur }\end{array}$ & 1 & 2 & $9-14$ & $\begin{array}{l}\text { Operation performed as part of van } \\
\text { Nes procedure, and repeated }\end{array}$ \\
\hline Post-meningitic paresis & 1 & 2 & 5 & \\
\hline
\end{tabular}

\section{ADVANTAGES OF THE METHOD}

Since no internal fixation is required the position of the leg may be adjusted when the first plaster is changed.

A poorly developed bone is not weakened by this operation as it is by the removal of a wedge of bone as in the O'Donoghue (1940) method. If the deformity recurs the operation may be repeated, as was successfully done in one patient in this series.

\section{SUMMARY}

1. "Reed" osteotomy has proved a satisfactory method for the correction of torsional deformity of the tibia and of associated minor varus or valgus deformity.

2. It is an "osteotomy in continuity" and maintains stability of the bone.

3. The position of the limb may be adjusted at the first change of plaster.

4. Three cases of non-union occurred in thirty-eight operations.

5. The operation should not be done on adults. Perhaps it may be wise to reserve it for even younger patients because its success depends on the pliability of cortical bone, which rapidly diminishes with increasing age.

I wish to thank the staff of the Royal National Orthopaedic Hospital, and Mr H. J. Seddon in particular, for permission to publish this report of cases treated by them. I am indebted to Mr R. J. Whitley, F.R.P.S., of the Clinical Photographic Department, Institute of Orthopaedics, for the photographs.

\section{REFERENCES}

CAmpbell, W. C. (1939): Operative Orthopedics. London: Henry Kimpton.

HAAS, S. L. (1929): Longitudinal Osteotomy. Journal of the American Medical Association, 92, 1656.

Nes, C. P. VAN (1950): Rotation-plasty for Congenital Defects of the Femur. Journal of Bone and Joint Surgery, 32-B, 12.

O'Donoghue, D. H. (1940): Controlled Rotation Osteotomy of the Tibia. Southern Medical Journal, 33, 1145. SEdDoN, H. J. (1956): Personal communication.

VOL. 39 B, NO. 4, NOVEMBER 1957 